\title{
Retrospective comparison of 'Cheno' and 'Urso' in the medical treatment of gallstones*
}

\author{
T J MEREDITH, G V WILLIAMS, $\dagger$ P N MATON, $\ddagger \mathrm{G}$ M MURPHY, \\ H M SAXTON, and R HERMON DOWLING $\S$
}

\begin{abstract}
From the Gastroenterology Unit, Departments of Medicine and Diagnostic Radiology, Guy's Hospital and Medical School, London
\end{abstract}

SUMMARY In two groups of gallstone patients ideally suited for medical treatment, the effect of six to 18 months' therapy was compared retrospectively in 52 given chenodeoxycholic acid (CDCA) and 46 given ursodeoxycholic acid (UDCA). The minimum dose $\left(\mathrm{mg} \mathrm{kg}^{-1} \mathrm{day}^{-1}\right)$ required to desaturate bile consistently was $10 \cdot 1$ for UDCA and 14.3 for CDCA. In patients completing six months' treatment, 23 of $35(66 \%)$ taking a mean of $7 \cdot 7$ ( \pm SEM 0.5$)$ mg UDCA and 34 of $42(81 \%)$ taking $14 \cdot 7 \pm 0 \cdot 2 \mathrm{mg}$ CDCA showed partial or complete dissolution of gallstones. The mean dose in the UDCA-treated patients, however, was artefactually lowered by previous dose-response studies: in those who had not taken multiple doses, the mean UDCA intake in the 'responders' at six months was $9 \cdot 1 \pm 0.3 \mathrm{mg} \mathrm{kg}^{-1} \mathrm{day}^{-1}$. At six months, more UDCA (five of 35 or $14.3 \%$ ) than CDCA (four of 42 or $9.5 \%$ )-treated patients showed complete dissolution of gallstones, but, by one year, the situation was reversed, 20 of $41(49 \%)$ CDCA-treated and eight of $30(27 \%)$ UDCA-treated patients showing complete dissolution of gallstones. Cumulative efficacy at one year had risen to $76 \%$ for UDCA and $89 \%$ for CDCA. Both treatments reduced the frequency of dyspepsia and biliary colic; 37\% of CDCA and $2.6 \%$ of UCDA-treated patients showed hypertransaminasaemia; diarrhoea developed in $60 \%$ of the CDCA group but in none of the UDCA group.

Chenodeoxycholic acid (CDCA) and ursodeoxycholic acid (UDCA) are both established as effective treatments for patients with cholesterol-rich gallstones. ${ }^{1-10}$ UDCA is the more recent of the two drugs but it is not yet clear whether it will replace CDCA as the medical treatment of choice for dissolution of gallstones.

The efficacy of treatment for dissolving gallstones depends on careful selection of patients and, with CDCA treatment, the best results are seen in non-obese patients given $13-15 \mathrm{mg} \mathrm{kg}^{-1} \mathrm{day}^{-1}$, who have radiolucent (presumed cholesterol-rich) gallstones measuring less than $15 \mathrm{~mm}$ in diameter in functioning gallbladders. ${ }^{11}$ By deliberately selecting patients who fulfilled these criteria, we were able to compare, retrospectively, the efficacy of six, 12 , and

\footnotetext{
* Presented in part at the Annual Meeting of the British Society of Gastroenterology, Edinburgh, 1978, and published in abstract form. ${ }^{23}$

$\dagger$ Present address: Freeman Hospital, Newcastle upon Tyne.

¥ Present address: Royal Postgraduate Medical School, Du Cane Road, London W12.

§ Address for correspondence: RHD at Guy's Hospital, London SE1 9RT.

Received for publication 25 September 1981
}

18 months' treatment with CDCA and UDCA in diminishing the saturation of bile with cholesterol and in dissolving gallstones. We also compared the frequency and severity of symptons (such as biliary colic and non-specific dyspepsia) and the incidence of side-effects, before and during treatment. This paper reports our findings.

\section{Methods}

\section{PATIENTS}

Fifty-two patients treated with CDCA and 46 treated with UDCA fulfilled the criteria listed above and were selected for the comparative study. Details of their ages, sex ratios, and body weights are summarised in Table 1. There were no significant differences between the groups for any of these variables. Obese patients, arbitrarily defined as more than $130 \%$ of ideal body weight, were deliberately excluded from the comparative study because they are known to be relatively resistant to CDCA therapy. ${ }^{12}$ 
Table 1 Clinical details in two groups of non-obese gallstone patients all of whom had radiolucent stones measuring less than $15 \mathrm{~mm}$ in diameter in functioning gallbladders

\begin{tabular}{lll}
\hline & $\begin{array}{l}U D C A \\
(n=46)\end{array}$ & $\begin{array}{l}C D C A \\
(n=52)\end{array}$ \\
\hline Age (yr) & $53 \cdot 2 \pm 2 \cdot 2$ & $51 \cdot 7 \pm 2 \cdot 6$ \\
F:M ratio & $2 \cdot 5: 1$ & $4 \cdot 1: 1$ \\
Weight $(\mathrm{kg})$ & $66 \cdot 8 \pm 1 \cdot 5$ & $67 \cdot 2 \pm 2 \cdot 6$ \\
\% ideal body weight & $115 \pm 3 \cdot 1$ & $119 \pm 2 \cdot 9$ \\
\hline
\end{tabular}

UDCA = ursodeoxycholic acid CDCA = chenodeoxycholic acid.

Results are means \pm SEM's. $F: M=$ female : male.

\section{RADIOLOGY BEFORE AND DURING TREATMENT}

Oral cholecystograms were carried out not more than three months before starting treatment (baseline radiographs) and at six monthly intervals during therapy. 'Functioning' gallbladders were defined as those which opacified well after contrast material and contracted in response to a fatty meal. Gallstone size was based on the maximum diameter of the largest stone measured on standardised cholecystogram films (ignoring the small error which results from magnification on the radiographs).

During treatment, partial gallstone dissolution was defined as an unequivocal reduction in gallstone size and/or number as agreed by three observers (one radiologist and two physicians). Complete gallstone dissolution was accepted only if two consecutive cholecystograms, three months apart, showed no evidence of gallstones remaining on erect films taken with fluoroscopic control, as well as supine, prone, and after fatty meal films.

\section{BILE ACID THERAPY}

Source

Chenodeoxycholic acid (Chendol, Weddel Pharmaceuticals, London) was supplied in $125 \mathrm{mg}$ gelatin- coated capsules. Ursodeoxycholic acid (Deursil, Gipharmex Company, Milan) was supplied in 150 mg capsules.

\section{Dose}

In all patients, the bile acid dose was based on body weight. Apart from the previously reported ${ }^{16}$ studies in which the minimum CDCA dose found to desaturate bile (see below) was determined, all CDCA-treated patients ${ }^{11}$ were given $13-15 \mathrm{mg}$ $\mathrm{kg}^{-1} \mathrm{day}^{-1}$. The dose of UDCA varied from patient to patient. Eleven of the UDCA-treated patients had taken part in a previous dose-response study, ${ }^{5}$ each being treated for six weeks with five, 10 , and 15 mg UDCA kg ${ }^{-1} \mathrm{day}^{-1}$. Another five patients took part in an extension of this dose-response study each receiving $2 \cdot 5,5 \cdot 0$, and $10 \cdot 0 \mathrm{mg}$ UDCA kg $\mathrm{day}^{-1}$ (Fig. 1). The remaining 30 UDCA-treated patients were given $8-10 \mathrm{mg} \mathrm{kg}^{-1} \mathrm{day}^{-1}$. With both treatments, the bile acid capsules were taken with meals in two or three divided doses throughout the day. Bile lipid composition was measured after six weeks' treatment on each dose. At the end of the six to 18 week dose-response studies, UDCA treatment was continued at the lowest dose which had been found to produce desaturation of fasting duodenal bile with cholesterol (see below). The following criteria were used to compare the doses of the two bile acids:

1 The minimum dose of CDCA or UDCA during which fasting duodenal bile became unsaturated in cholesterol (arbitrarily defined as a post-treatment saturation index of less than 1.0 according to the limits of cholesterol solubility in bile as determined by Hegardt and Dam, ${ }^{13}$ Holzbach and others ${ }^{14}$ ). In the case of the UDCA-treated patients, no correction was made for the reduced equilibrium cholesterol solubility known to occur in vitro in UDCA-rich bile. ${ }^{15}$
Fig. 1 Effect of different doses of UDCA on the cholesterol saturation index in fasting bilerich duodenal fluid according to the solubility criteria ${ }^{13}$ of Hegard and Dam $(H+D)$, in individual patients.

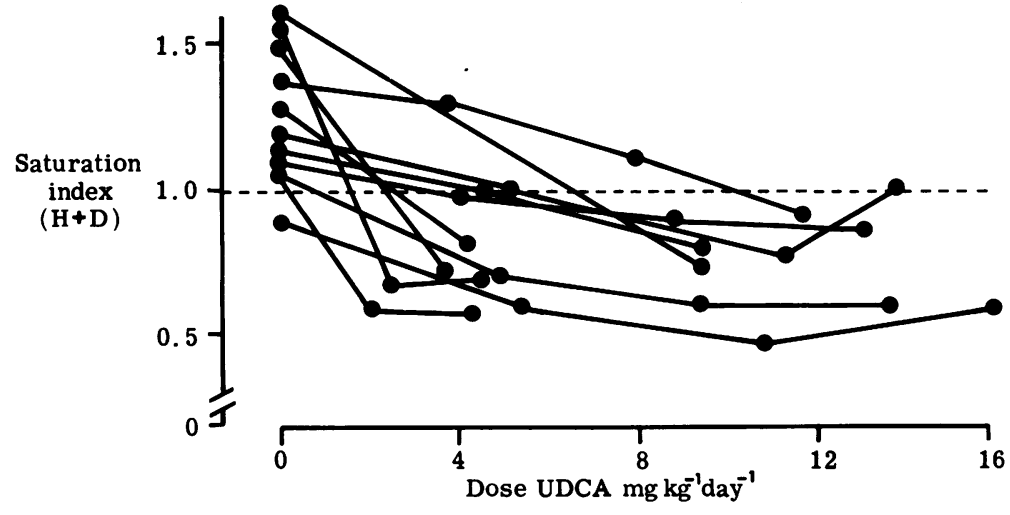


2 The minimum bile acid dose required to produce unsaturated bile, as defined above, in all patients. 3 The mean bile acid dose required to produce gallstone dissolution (either partial or complete) after six and 12 months' treatment.

In the case of the 16 UDCA-treated patients who took part in the bile-lipid, dose-response studies, the dose required to produce gallstone dissolution was calculated by multiplying the daily dose (mg UDCA $\mathrm{kg}^{-1}$ ) by the number of weeks at that dose level and taking the mean over the six or 12 month period when the cholecystogram first became normal. To exclude the possibility that the varying initial dose could have biased the results, the mean UDCA dose found to produce complete gallstone dissolution was calculated separately for the responders who took part in the dose-response studies over the first six to 18 weeks and for those who took constant UDCA doses throughout (Table 2).

We, and others, have previously shown that there is a significant linear relationship between biliary cholesterol saturation index and the dose of $\mathrm{CDCA}^{16}$ and $\mathrm{UDCA}^{5}$ expressed in $\mathrm{mg} \mathrm{kg}^{-1}$ day $^{-1}$. In the present study we looked at the relationship between these variables in individual patients treated for six week periods with different UDCA doses.

\section{BILE LIPID ANALYSIS}

Fasting, bile-rich fluid was aspirated from the duodenum after stimulating gallbladder contraction with 50-100 units of intravenous cholecystokinin (Pancreozymin, Boots, Nottingham). The samples were stored at $-20^{\circ} \mathrm{C}$ until analysed for their bile acid, phospholipid, and cholesterol content as previously described. ${ }^{5}$ The resultant biliary cholesterol saturation indices were calculated using the poly- nomial equation described by Thomas and Hofmann ${ }^{17}$ and the cholesterol solubility criteria described above.

EFFICACY OF TREATMENT IN PRODUCING PARTIAL OR COMPLETE GALLSTONE DISSOLUTION

The efficacy of treatment was assessed by comparing results for partial or complete gallstone dissolution after six, 12, and 18 months' CDCA and UDCA therapy.

\section{FOLLOW-UP: SYMPTOMS AND SIDE-EFFECTS}

During treatment, the patients were assessed as outpatients every one to two months. Fasting serum lipids and liver 'function' tests (see below) were checked at each visit and the frequency and severity of symptoms associated with gallstones, and of side-effects attributable to therapy, were noted. In particular, the presence or absence of diarrhoea, dyspepsia, and pain suggestive of biliary colic were recorded. Diarrhoea was arbitrarily defined as two or more loose motions per day in patients who had previously passed normal stools. Non-specific dyspeptic symptoms included bloating, belching, heartburn, and fat intolerance. Biliary colic was diagnosed clinically from a history of steady epigastric and/or right hypochondrial pain of varying severity with - or, more usually, without - clinical and biochemical features of cholestasis.

\section{FASTING SERUM LIPIDS AND LIVER FUNCTION TESTS}

Fasting serum cholesterol and triglyceride levels together with serum gamma glutamyl transpeptidase $(\gamma \mathrm{GT})$, bilirubin, aspartate amino-transferase (AAT), alkaline phosphatase (AP), total protein and albumin were measured in the hospital clinical chemistry laboratory.

Table 2 Effect of six and 12 months' treatment with UDCA and CDCA on gallstone (GS) dissolution - both partial and complete - in comparable groups of selected patients*

\begin{tabular}{|c|c|c|c|c|c|c|}
\hline & \multicolumn{3}{|c|}{ Patients } & \multicolumn{3}{|c|}{ Bile acid dose $\left(\mathrm{mg} \mathrm{kg}^{-1}\right.$ day $\left.^{-1}\right)$ in 'responders' } \\
\hline & \multirow[b]{2}{*}{ Total } & \multicolumn{2}{|c|}{ GS dissolution } & \multirow[b]{2}{*}{ All patients } & \multirow{2}{*}{$\begin{array}{l}\text { Patients in } \\
\text { dose-response } \\
\text { studies }\end{array}$} & \multirow{2}{*}{$\begin{array}{l}\text { Patients not in } \\
\text { dose-response } \\
\text { studies }\end{array}$} \\
\hline & & Partial & Complete & & & \\
\hline \multicolumn{7}{|l|}{ UDCA } \\
\hline 6 months & 35 & 18 & 5 & $7 \cdot 7 \pm 0 \cdot 55$ & $6 \cdot 25 \pm 0 \cdot 6(n=10)$ & $9 \cdot 07 \pm 0 \cdot 3(n=13)$ \\
\hline 12 months $\dagger$ & 30 & 16 & 8 & $7 \cdot 4 \pm 0 \cdot 8$ & $6 \cdot 26 \pm 0 \cdot 8(n=12)$ & $9 \cdot 26 \pm 0 \cdot 6(n=7)$ \\
\hline \multicolumn{7}{|l|}{ CDCA } \\
\hline 6 months & 42 & 30 & 4 & $14 \cdot 7 \pm 0 \cdot 2$ & - & - \\
\hline 12 months $\dagger$ & 41 & 13 & 20 & $14 \cdot 3 \pm 0 \cdot 2$ & - & - \\
\hline
\end{tabular}

* The mean doses of the two bile acids found to produce this effect in the 'responders' (patients showing radiological evidence of either partial or complete gallstone dissolution), are also shown. For the UDCA-treated patients, the results are given for all patients showing partial or complete gallstone dissolution and for two subgroups - those who took part in dose-response studies during the first six to 18 weeks of treatment and those who did not.

$\dagger$ Cumulative results for complete gallstone dissolution. 
Results

DOSE

Minimum dose desaturating bile in any one patient This was found to be $2 \cdot 1 \mathrm{mg}$ for UDCA and $4.0 \mathrm{mg}$ $\mathrm{kg}^{-1}$ day $^{-1}$ for CDCA. ${ }^{*}$

\section{Minimum dose consistently desaturating bile in all patients}

This was found to be $10.1 \mathrm{mg}$ for UDCA and 14.3 mg kg${ }^{-1}$ day $^{-1}$ for CDCA.*

The effect of different UDCA doses (mg $\mathrm{kg}^{-1} \mathrm{day}^{-1}$ ) on the biliary cholesterol saturation indices in individual patients is shown in Fig. 1. From these data it seems that the relationship between these variables is curvilinear rather than linear.

\section{Mean dose producing gallstone dissolution in 'responders'}

The UDCA dose in the 23 'responders' who showed radiological evidence of partial or complete gallstone dissolution after six months' therapy (Table 2) was $7.7 \pm$ SEM $0.5 \mathrm{mg} \mathrm{kg}^{-1} \mathrm{day}^{-1}$. The corresponding dose of CDCA in the 34 responders treated for six months was $14 \cdot 7 \pm 0 \cdot 2 \mathrm{mg} \mathrm{kg}{ }^{-1} \mathrm{day}^{-1}$, which was significantly greater than the UDCA dose $(p<0.001)$. Thirty of the UDCA-treated and 41 of the CDCA-treated patients went on to complete 12 months' therapy (or stopped treatment because complete gallstone dissolution had been confirmed cumulative results). Of these, there were 24 responders (16 partial and eight complete) in the UDCA group and 33 (13 partial and 20 complete) in the CDCA group. The mean UDCA dose $(7 \cdot 4 \pm 0 \cdot 8$ mg kg-1 $\mathrm{day}^{-1}$ ) in patients showing evidence of gallstone dissolution after one year's treatment was similar to that seen after six months' ursotherapy and again significantly less $(p<0 \cdot 001)$ than the dose in the corresponding group of patients treated with CDCA for one year $\left(14 \cdot 3 \pm 0 \cdot 2 \mathrm{mg} \mathrm{kg}^{-1} \mathrm{day}^{-1}\right)$. As the results in Table 2 show, however, the amounts of UDCA found to produce gallstone dissolution in the responders were considerably distorted by the previous dose-response studies. In patients showing radiological evidence of response at six months, the mean dose in those who had taken multiple UDCA doses was $6 \cdot 25 \pm 0 \cdot 6$ compared with $9 \cdot 07 \pm 0 \cdot 3$ in those who had not $(p<0.001)$. At 12 months, the corresponding figures were almost identical $(6 \cdot 26 \pm 0 \cdot 8$ versus $9 \cdot 26 \pm 0 \cdot 6 ; p<0 \cdot 001)$.

\footnotetext{
* As previously stated, the minimum CDCA doses found to desaturate bile were based on previously published results. ${ }^{16}$
}

EFFICACY OF TREATMENT IN PRODUCING PARTIAL OR COMPLETE GALLSTONE DISSOLUTION (Table 2) Thirty-five patients completed six months' treatment with UDCA. Of these, twenty-three (66\%) showed evidence of gallstone dissolution (five complete and 18 partial) compared with 34 of 42 patients $(81 \%)$ given CDCA over the same time period (four complete and 30 partial). The corresponding figures at one year were 19 of 25 patients $(76 \%)$ treated with UDCA and 33 of 37 treated with CDCA $(89 \%) .+$ The proportion of patients whose gallstones dissolved completely after one year's treatment was less $(0.02<\mathrm{p}<0.05)$ for UDCA - eight of $30(27 \%)$ - than for CDCA - 20 of 41 (49\%), perhaps as a result of the dose-response studies during which some of the UDCA-treated patients took suboptimal doses for up to 12 weeks.

Twelve patients in the UDCA group were treated for 18 months or more. In eight of these, the gallstones showed progressive, but as yet incomplete, dissolution, while two showed complete dissolution of gallstones at radiography 18 months after treatment. Another patient, whose gallstones remained unchanged despite ursotherapy, was found on follow-up radiography to have radioopaque calcified rims to her gallstones: Because the quality of the initial radiography in this patient was indifferent, it was not possible to say whether the calcification was present before treatment or whether it was acquired during therapy. In the twelfth patient, because the radiographs remained unchanged in spite of 18 months' treatment with an adequate dose of UDCA $\left(10.8 \mathrm{mg} \mathrm{kg}^{-1} \mathrm{day}^{-1}\right)$, unsaturated bile (an on-treatment saturation index of 0.60 ) and UDCA-enriched bile (UDCA conjugates accounting for $42 \%$ of the biliary bile acids), radiolucent non-cholesterol gallstones were suspected. This was subsequently confirmed: at cholecystectomy small pigment-rich stones were removed which, on analysis, were found to contain no measurable amounts of cholesterol.

\section{SYMPTOMS AND SIDE-EFFECTS}

The incidence of non-specific dyspeptic symptoms before and during bile acid treatment and the frequency of episodes of biliary colic, comparing the incidence in the years before treatment with that seen during six to 18 months' therapy, are shown in 'pie-graph' form in Fig. 2.

\section{Non-specific dyspepsia (Fig. 2, left panel)}

Before treatment, $67 \%$ of patients complained of non-specific abdominal symptoms but during

t These cumulative efficacy figures include the results in patients showing complete dissolution of gallstones at six months. ${ }^{18}$ 
Fig. 2 Effect of treatment with $C D C A$ and $U D C A$ on the frequency of non-specific dyspepsia (for definition, see text) - left panel-and biliary colic-right panel-before and during treatment. The 'fractions' indicate the number of patients admitting to symptoms, over the total number of patients studied, together with the percentage of patients affected. The shaded zones indicate the percentage of patients with symptoms.
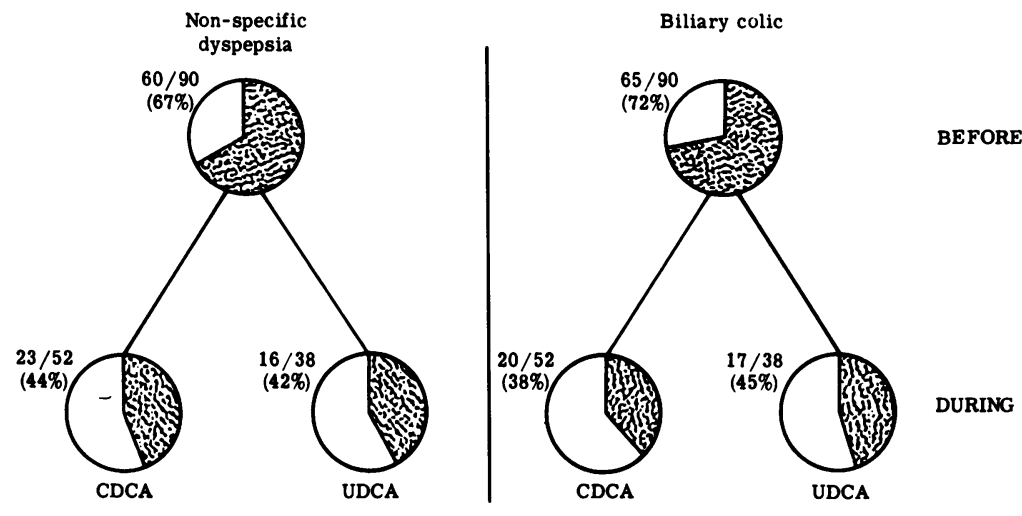

therapy with both bile acids there was a reduction in these dyspeptic complaints, the apparent benefit being comparable with chenotherapy (to $44 \%$ ) and ursotherapy (to $42 \%$ ).

Biliary colic (Fig. 2, right panel)

Biliary colic was present in $72 \%$ of patients before bile acid treatment, but dropped to $38 \%$ with CDCA and $45 \%$ with UDCA. As in our earlier studies, ${ }^{1116}$ the reduction in the frequency and severity of biliary colic seemed independent of gallstone dissolution.

\section{Diarrhoea}

Before bile acid treatment, diarrhoea was present in only one of 90 patients. In this case, the frequent bowel movements seemed, on clinical grounds, to be due to a spastic or irritable colon. The patient was treated with UDCA, which did not change his bowel habit. With this one exception, diarrhoea never occurred during ursotherapy but it affected $60 \%$ (31 of 52 patients) of the CDCA-treated group. By the Chi-square test, this difference was statistically significant $(p<0 \cdot 01)$. As noted before, however, this diarrhoea tended to resolve spontaneously with time and, after the initial few weeks of treatment, persistent or intermittent diarrhoea affected only $13(25 \%)$ of the patients treated with CDCA.

\section{LIVER FUNCTION TESTS AND SERUM LIPIDS}

There were no significant differences between the pre- and on-treatment (measured after six to 12 weeks of therapy) results nor between the CDCAand UDCA-treated patients for serum bilirubin, alkaline phosphatase, total protein, and albumin levels. However, 19 of the 52 patients treated with CDCA $(37 \%)$ showed raised serum transaminase levels (never exceeding three times normal) at some time during the first six months' treatment. In contrast, only one of the 46 patients treated with UDCA ever developed hypertransaminasaemia and then only transiently after an attack of biliary colic.

The mean fasting serum triglyceride levels fell by $12 \%$ during CDCA therapy and by up to $30 \%$ in the patients given comparable doses of UDCA. These on-treatment levels were not statistically different from the pre-treatment values for CDCA, but there were significant falls in the mean levels during UDCA treatment with the 10 and $15 \mathrm{mg} \mathrm{kg}^{-1} \mathrm{day}^{-1}$ doses. These serum lipid results have been reported elsewhere. ${ }^{19}$ There were no significant differences in mean fasting serum cholesterol levels before and during treatment nor between the CDCA- and UDCA-treated patients.

\section{Discussion}

The purpose of this paper was to compare and contrast CDCA and UDCA in the medical treatment of gallstones. The results provide objective evidence about the dose and efficacy of the two bile acid treatments in producing gallstone dissolution and extend the results of uncontrolled observations about the frequency and severity of symptoms and side-effects seen during therapy. Our findings confirm that UDCA is as effective as CDCA in desaturating bile and is almost as effective as CDCA in dissolving gallstones but that it does so at half to two-thirds the dose of CDCA and with fewer side-effects.

Although the present study was retrospective, rather than the more desirable prospective randomallocation type of study, the groups were, nonetheless, broadly comparable. By virtue of its design, the result of the present study was to achieve a comparable effect on the saturation index of biliary cholesterol with different bile acid doses. An alternative approach would have been to have used comparable bile acid doses to see whether or not 
UDCA was more effective than CDCA in desaturating bile and in promoting more rapid dissolution of gallstones. The latter approach has already been adopted for studies of bile lipid composition. In a crossover study on 10 patients, Stiehl et al. ${ }^{20}$ compared the effects of approximately 15 (range 12.7-17.9) $\mathrm{mg}$ of UDCA kg${ }^{-1} \mathrm{day}^{-1}$ and of the same doses of CDCA, on fasting biliary cholesterol saturation. They showed that with CDCA, the mean on-treatment saturation index was $0 \cdot 8 \pm 0 \cdot 1$, while with UDCA it was $0 \cdot 6 \pm 0 \cdot 1$. By implication, therefore, one might expect more rapid gallstone dissolution with UDCA. As yet, there have been few studies in man where gallstone dissolution rates have been correlated with the degree of desaturation of bile during treatment, but the results of studies in the Rhesus monkey suggest that the speed of gallstone dissolution is indeed inversely related to biliary cholesterol saturation. ${ }^{21}$

The present results show that, in some patients, desaturation of fasting duodenal bile can occur with doses as small as $4.0 \mathrm{mg} / \mathrm{kg}$ for CDCA and $2.1 \mathrm{mg} / \mathrm{kg}$ for UDCA. These results with CDCA lend indirect support to Danzinger's findings ${ }^{22}$ that gallstone dissolution occurs occasionally with small CDCA doses. However, the recommended bile acid dose should not be the minimum dose which desaturates bile but the one which does so consistently. From the results of the present and other studies, ${ }^{11}{ }^{23}$ we would still recommend a dose of 7-10 mg UDCA $\mathrm{kg}^{-1} \mathrm{day}^{-1}$ and 13-15 mg CDCA kg ${ }^{-1} \mathrm{day}^{-1}$.

Our initial observation that saturation index and the dose of CDCA (expressed in $\mathrm{mg} \mathrm{kg}^{-1} \mathrm{day}^{-1}$ ) are linearly related, ${ }^{16}$ has now been confirmed by others $^{24}$ but the present results suggest that for UDCA, this relationship is curvilinear rather than linear. By including the saturation values before treatment $\left(0 \mathrm{mg} \mathrm{UDCA} \mathrm{kg}{ }^{-1} \mathrm{day}^{-1}\right)$, it was possible to show a significant linear relationship between the saturation index and the daily dose of UDCA $(n=53 ; r=0.52 ; p<0 \cdot 001)$. When the pretreatment values were excluded, however, this relationship no longer held true, suggesting that once bile became desaturated to within the therapeutic range ${ }^{11}$ (ontreatment saturation indices of approximately $0 \cdot 8$ ), there was no additional benefit to be gained by increasing the dose of UDCA.

Clearly, many patients will develop unsaturated bile with less UDCA than the recommended dose. Indeed, it has even been suggested that it is a disadvantage to have UDCA-rich bile for gallstone dissolution because in UDCA-rich 'bile' there is slower dissolution of artificial cholesterol gallstones (cholesterol monohydrate discs) ${ }^{25}$ and a more reduced equilibrium cholesterol solubility, ${ }^{15}$ than in bile of mixed bile acid composition. The fact remains, however, that in equimolar doses $(15 \mathrm{mg}$ $\left.\mathrm{kg}^{-1} \mathrm{day}^{-1}\right)$, UDCA reduces biliary cholesterol secretion more than CDCA. ${ }^{26}$ This advantage seems to outweigh the hypothetical disadvantage of having UDCA-rich bile, as the present results clearly show that, before applying correction factors, $7-10 \mathrm{mg}$ UDCA $\mathrm{kg}^{-1}$ day $^{-1}$ desaturated bile and dissolved gallstones. Had we applied correction factors for the bile acid glycine: taurine ratio and for the percentage of UDCA in biliary bile acids, ${ }^{15}$ paradoxically we would have shown gallstone dissolution despite persistence of supersaturated fasting duodenal bile. $^{27}$

Why UDCA produces comparable desaturation of bile to CDCA, but at lower doses, is uncertain, but already a few facts are clear. Firstly, Federowski et al. ${ }^{28}$ have shown that the bacterial degradation of CDCA to lithocholic acid in vitro is more rapid than that of UDCA. By implication, therefore, relatively more 'non-degraded' UDCA would be left available for absorption and therapeutic effect during ursotherapy than CDCA during chenotherapy. Secondly, CDCA and UDCA are believed to dissolve cholesterol gallstones by reducing biliary cholesterol secretion ${ }^{26}{ }^{29}$ which, in turn, leads to the formation of unsaturated fasting gallbladder bile. Possible mechanisms for this effect include: (1) reduction of hepatic cholesterol synthesis (as judged by inhibition of the rate-limiting enzyme in cholesterogenesis, HMGCoA reductase ${ }^{30-32}$ (2) diminution of cholesterol absorption, ${ }^{33-35}$ (3) an acute effect of CDCA-rich and UDCA-rich bile on the pattern of lipid secretion by the hepatocyte across the canalicular membrane into bile. 36

While desaturation of fasting duodenal bile and radiological signs of partial gallstone dissolution provide useful interim evidence of a response to treatment, ultimately the efficacy of bile acid therapy must be judged on complete gallstone dissolution. Despite the relatively small number of UDCA-treated patients in the present study and the sometimes short duration of therapy, one can, nonetheless, still make useful observations about the efficacy of treatment in producing partial or complete gallstone dissolution.

The efficacy of six months' treatment with the two bile acids was high, although at both six and 12 months, the 81 and $89 \%$ efficacy figures for CDCA were higher than the corresponding figures for UDCA (66 and $76 \%$ respectively). This nonsignificant difference may be due to the fact that some of the 16 UDCA-treated patients who took part in the dose-response studies had suboptimal UDCA doses for the first six to 12 weeks of their study.

The reduction in dyspeptic symptoms and in the 
frequency and severity of biliary colic seen during treatment with both bile acids extends previous uncontrolled observations from our own unit ${ }^{16}$ and elsewhere. ${ }^{38}$ The strong possibility that this is a placebo effect has been made less likely by the results of two short-term, double-blind trials comparing UDCA and placebo. ${ }^{39}{ }^{40}$ The mechanism for these apparent benefits is unknown and is currently under study in our unit. ${ }^{45}$

Given their structural similarities, it might at first sight seem surprising that treatment with CDCA should result in hypertransaminasaemia while treatment with its $7 \beta$ epimer, UDCA, does not. However, the apparently minor positional change of the 7 hydroxyl group results in quite marked differences in the spatial relationship between 3 and 7 hydroxyl groups on the molecule and this could well alter the surface-active properties of the two bile acids. Indeed, this explanation has been advanced to explain the differences in the incidence of diarrhoea seen with CDCA and UDCA. ${ }^{41}$

When comparing the pros and cons of CDCA and UDCA, two other aspects merit discussion - the development of calcified rims to gallstones during therapy and the possibility that the cost and sideeffects of CDCA treatment might be reduced by low-dose, bedtime administration of the bile acid. In the present study, one patient seemed to have developed calcification at the periphery of his gallstone during treatment which may well render further dissolution therapy ineffective. To date, there is little published information about this phenomenon, but several groups have reported similar findings. ${ }^{42}{ }^{43}$ Whether this occurs more often during bile acid therapy than would happen spontaneously, whether it occurs only with UDCA and not with CDCA and whether, as a predisposing factor, calcium solubility is impaired in UDCA-rich bile, remains to be proven. Similarly, Northfield's group have shown that low-dose, bedtime administration of CDCA desaturates fasting duodenal bile and produces partial gallstone dissolution more rapidly than divided CDCA doses. ${ }^{44}$ If more rapid or effective complete gallstone dissolution is proved by this group and confirmed by others and if this benefit is specific to CDCA and not to UDCA, then the apparent advantages of UDCA might well be negated.

We are grateful to Weddel Pharmaceuticals Limited, London for supplies of CDCA (Chendol) and to the Gipharmex Company, Milan for UDCA (Deursil). We wish to thank Dr James Liddell and his colleagues in the Department of Clinical Chemistry for the routine laboratory results and $\mathrm{Mr}$
Younus Qureshi for his valuable technical assistance. TJM and GVW were Giuliani fellows, PNM was supported by Weddel Pharmaceuticals, and GMM is supported by the Wellcome Trust.

\section{References}

1 Bell GD, Whitney B, Dowling RH. Gallstone dissolution in man using chenodeoxycholic acid. Lancet 1972; 2: 1213-6.

2 Danzinger RG, Hofmann AF, Schoenfield LJ, Thistle JL. Dissolution of cholesterol gallstones by chenodeoxycholic acid. $N$ Engl J Med 1972; 286: 1-8

3 Makino I, Shinozaki K, Yoshino K, Nakagawa S. Dissolution of cholesterol gallstones by ursodeoxycholic acid. Jap J Gastroenterol 1975; 72: 690-702.

4 Stiehl A, Cyzgan P, Kommerell B, Weis HJ, Holtermuller KH. Ursodeoxycholic acid versus chenodeoxycholic acid: a comparison of their effect on bile acids and cholesterol saturation in bile of patients with cholesterol gallstones. Digestion 1977; 16: 323A.

5 Maton PN, Murphy GM, Dowling RH. Ursodeoxycholic acid treatment of gallstones: dose response study and possible mechanism of action. Lancet 1977; 2: 1297-1301.

6 Kutz C, Schulte A. Effectiveness of ursodeoxycholic acid in gallstone dissolution. (Letter). Gastroenterology 1977; 73: 632-3.

7 Nakagawa S, Makino I, Ishizaki T, Dohi I. Dissolution of cholesterol gallstones by ursodeoxycholic acid. Lancet 1977; 2: 367-69.

8 Nakayama F. Oral cholelitholysis - Cheno versus Urso. Japanese experience. Dig Dis Sci 1980; 25: 129-34.

9 Tokyo Co-operative Gallstone Study Group. Efficacy and indications of ursodeoxycholic acid treatment for dissolving gallstones. Gastroenterology 1980; 78: 542-8.

10 Salen G, Colalillo A, Verga D, Bagan E, Tint GS, Shefer S. Effect of high and low doses of ursodeoxycholic acid on gallstone dissolution in humans. Gastroenterology 1980; 78: 1412-8.

11 Iser JH, Dowling RH, Mok HYI, Bell GD. Chenodeoxycholic acid treatment of gallstones: a follow-up report and analysis of factors influencing response to therapy. $N$ Engl J Med 1975; 293: 378-83.

12 Iser JH, Maton PN, Murphy GM, Dowling RH. Resistance to chenodeoxycholic acid treatment in obese patients with gallstones. $\mathrm{Br}$ Med J 1978; 1: 1509-12.

13 Hegardt F, Dam $H$. The solubility of cholesterol in aqueous solutions of bile salts and lecithin. $Z$ Ernaehrungswiss 1971; 10: 228-33.

14 Holzbach RT, Marsh M, Olszewski M, Holan K. Cholesterol solubility in bile. Evidence that supersaturated bile is frequent in healthy man. J Clin Invest 1973; 52: 1467-79.

15 Carey MC. Critical tables for calculating the cholesterol saturation of native bile. J Lipid Res 1978; 19: 945-55.

16 Mok HYI, Bell GD, Dowling RH. Effect of different 
doses of chenodeoxycholic acid on bile lipid composition and frequency of side-effects in patients with gallstones. Lancet 1974; 2: 253-7.

17 Thomas PJ, Hofmann AF. A simple calculation of the lithogenic index of bile: expressing biliary lipid composition on rectangular co-ordinates. (Letter). Gastroenterology 1973; 65: 689-700.

18 Maton PN, Iser JH, Murphy GM, Dowling RH. Efficacy of, withdrawal from, and resistance to chenodeoxycholic acid treatment in patients with gallstones. (Abstract). Gut 1977; 18: A976.

19 Williams G, Murphy GM, Dowling RH. Effect of ursodeoxycholic acid (UDCA) on serum total and VLDL triglycerides in gallstone patients. (Abstract). Clin Sci 1980; 58: 15P.

20 Stiehl A, Czygan P, Kommerell B, Weis HJ, Holtermuller KH. Ursodeoxycholic acid versus chenodeoxycholic acid: comparison of their effects on bile acid and bile lipid composition in patients with cholesterol gallstones. Gastroenterology 1978; 75: 1016-20.

21 Bell GD, Sutor DJ, Whitney B, Dowling RH. Factors influencing human gallstone dissolution in monkey, dog and human bile. (Abstract). Gut 1972; 13: A836.

22 Danzinger RG. Very low dose oral chenodeoxycholic acid (CDCA) will produce non lithogenic bile and dissolve gallstones. (Abstract). Gastroenterology 1977; 72: A12.

23 Williams G, Maton PN, Murphy GM, Dowling RH. Will ursodeoxycholic acid (UDCA) replace chenodeoxycholic acid (CDCA) as the medical treatment of choice for gallstone dissolution? (Abstract). Gut 1978; 19: A974.

24 Thistle JL, Hofmann AF, Yu PYS. Effect of varying doses of chenodeoxycholic acid on bile lipid and biliary bile acid composition in gallstone patients: a dose response study. Dig Dis Sci 1977; 22: 1-6.

25 Igimi H, Carey MC. Cholesterol monohydrate (ChM) gallstones dissolve faster in chenodeoxycholate (CDC)rich bile than in ursodeoxycholate (UDC)-rich bile. (Abstract). Gastroenterology 1980; 78: 1186.

26 von Bergmann K, Gutsfeld M, Schulze-Hagen K, von Unruh G. Effects of ursodeoxycholic acid on biliary lipid secretion in patients with radiolucent gallstones. In: Paumgartner G, Stiehl A, Gerok W, eds. Biological effects of bile acids. Lancaster: MTP Press, 1979: 61-6.

27 Williams G, Tanida N, Maton PN, Murphy GM, Dowling RH. Ursodeoxycholic acid (UDCA) therapy of gallstones. Is correction of biliary cholesterol saturation index according to percentage UDCA in bile necessary for prediction of gallstone dissolution? (Abstract). Clin Sci 1979; 57: 26.

28 Federowski T, Salen G, Tint S, Mosbach EH. Transformation of chenodeoxycholic acid and ursodeoxycholic acid by human intestinal bacteria. Gastroenterology 1979; 77: 1068-73. .

29 Northfield TC, La Russo NF, Hofmann AF, Thistle JL. Biliary lipid output during three meals and an overnight fast. II: Effect of chenodeoxycholic acid treatment in gallstone subjects. Gut 1977; 16: 12-7.

30 Salen G, Nicolau G, Shefer S. Chenodeoxycholic acid inhibits elevated hepatic HMGCoA reductase activity in subjects with gallstones. (Abstract). Clin Res 1973; 21: 523 .

31 Coyne MJ, Bonorris GG, Goldstein LI, Schoenfield LJ. Effect of chenodeoxycholic acid and phenobarbital on the rate limiting enzymes of hepatic cholesterol and bile acid synthesis in patients with gallstones. $J$ Lab Clin Med 1976; 87: 281-91.

32 Maton PN, Dowling RH. Hepatic cholesterol synthesis in cholelithiasis: role of HMGCoA reductase in response to, and resistance, to, medical treatment. Eur $J$ Clin Invest 1980; 10: 325-32.

33 Begemann F, Bandomer G, Herget HJ. The influence of betasitosterol on biliary cholesterol saturation and bile acid kinetics in man. Scand J Gastroenterol 1978; 13: $57-63$.

34 Ponz de Leon M, Carulli N, Loria P, Iori R, Zironi F. The effect of chenodeoxycholic acid (CDCA) on cholesterol absorption. Gastroenterology 1979; 77: 223-30.

35 Ponz de Leon M, Carulli N, Loria P, Iori R, Zironi F. Cholesterol absorption during bile acid feeding. Effect of ursodeoxycholic acid (UDCA) administration. Gastroenterology 1980; 78: 214-9.

36 Lindblad L, Lundholm K, Scherstén T. Influence of cholic and chenodeoxycholic acids on biliary cholesterol secretion in man. Eur J Clin Invest 1977; 7: 383-8.

37 Scherstén T, Lindblad L. Bile acid control of biliary cholesterol secretion in man. In: Bile acid metabolism in health and disease. Lancaster: MTP Press, 1977: 175-81.

38 James O, Cullen J, Bouchier IAD. Chenodeoxycholic acid therapy for gallstones: effectiveness, toxicity and influence on bile acid metabolism. $Q J$ Med 1975; 44: 349-67.

39 Frigerio G. Ursodeoxycholic acid (UDCA) in the treatment of dyspepsia: report of a multicentre controlled trial. Curr Ther Res 1979; 26: 214-24.

40 Polli E. The effect of ursodeoxycholic acid (UDCA) on dyspepsia in patients with gallstones or other biliary tract anomalies. Curr Ther Res 1979; 26: 230-2.

41 Chadwick VS, Gaginella TS, Debongnie JC, Phillips SF, Hofmann AF. Different effects of chenodeoxycholic and ursodeoxycholic acids on colonic secretion, permeability and morphology. (Abstract). Gastroenterology 1976; 71: 900.

42 Whiting MJ, Jarvinen V, Watts JMcK. Chemical composition of gallstones resistant to dissolution therapy with chenodeoxycholic acid. Gut 1980; 21: 1077-81.

43 Bateson MC, Bouchier IAD, Maudgal DP, Trash DB, Northfield TC. Calcification of radiolucent gallstones during treatment with ursodeoxycholic acid. $\mathrm{Br}$ Med J 1981; 283: 645-6.

44 Maudgal DP, Kupfer RM, Bird R, Northfield TC. Best buy bile acid treatment for gallstones. (Abstract). Gut 1980; 21: A910.

45 Meredith TJ, Hilson A, Murphy GM, Dowling RH. An explanation for bile-acid mediated gastritis and the relief of dyspepsia with chenodeoxycholic (CDCA) and ursodeoxycholic (UDCA) acid therapy (Abstract). Clin Sci 1981; 60: 22P. 